9

\title{
Language Diversity \& Practice in Higher Education: Can Discipline-Specific Language Instruction Improve Economics Learning Outcomes?
}

\author{
Trien Nguyen \\ University of Waterloo \\ Angela Trimarchi \\ Wilfrid Laurier University \\ Julia Williams \\ University of Waterloo
}

In the field of second language acquisition, discipline-specific language instruction is becoming widely known as Content and Language Integrated Learning. This method includes any activity that involves teaching a subject in a second language for the purpose of teaching both the subject content and the language. Research has shown that this two for one approach increases students' content knowledge and language proficiency in both the short and long terms (Baik \& Greig, 2009; Kasper, 1997; Song, 2006). These studies have been conducted using a variety of subjects in combination with several second languages, but the combination of economics and English has not been explored in the literature. Our research involved teaching English as an Additional Language (EAL) to international students taking an introductory economics course. Ten voluntary participants completed pre- and post-treatment assessments as well as exit interviews. Assessment results indicate that vocabulary instruction is correlated to success in economics although reading strategy instruction did not have the same impact. 


\section{Content and Language Learning in Higher Education}

Tn many universities, increased international recruitment has created a greater demand for English as an Additional Language (EAL) training. Despite having passed university English language requirements, EAL students often find language is still a barrier to academic success. At the postsecondary level, typical English language support courses are generic; that is, the content in these courses is not discipline-specific, but rather includes themes from a variety of popular topics. However, many EAL students need instruction in both language and content for their academic programs. Hyland (2002) uses a discipline-specific research model for language to show that university-level writing tasks are discipline specific. North (2005) concludes that "communication skills may be context-specific" (p. 518). Exploring the potential of discipline-specific second language instruction is, thus, essential to determining how language support can be delivered most efficiently so international students can overcome language barriers and become academically productive as soon as possible. Although the issue of generic versus discipline-specific instruction is relevant to other fields, our study looks specifically at its application to the field of EAL.

The discipline-specific model of second language instruction is widely known as Content and Language Integrated Learning. In Canada, French immersion programs have provided rich ground for research in second language acquisition at elementary and secondary levels. More recently, at postsecondary levels, studies have explored the provision of English language instruction through a variety of disciplines: architecture (Baik \& Greig, 2009), psychology, sociology, history, health and physical education (Song, 2006), geography (Rodgers, 2006), and psychology and physiology (Ready \& Wesche, 1992). These studies and others (Grabe \& Stohler, 1997) credit this approach with improving the target language proficiency while producing students who are at least as competent in their subject matter as students in control groups. Recent European and
North American experiments have produced strong second language proficiency and subject matter expertise while satisfying both students and teachers (Deen \& Hacquebord, 2002).

While these studies have paired second language instruction with a wide variety of disciplines, research combining English language instruction with the discipline of economics is not well represented in the literature. Economics provides an appropriate context for a pilot project because it is a popular field of study for international undergraduates. These students often struggle with economics concepts which have language connections. For example, terms such as the 'beggar thy neighbour' policy, 'keeping up with the Joneses' phenomenon, 'bandwagon' effect, and 'exchange rate appreciation' were coined by Anglophone economists in a cultural context not always clear to non-Anglophones. We wanted to find out whether discipline-specific second language instruction could help students improve their economics knowledge and English proficiency.

\section{An Environment for Economics and Language Instruction}

As the first economics course for most students is Introductory Microeconomics, we felt pairing English language instruction with this course would most likely provide results not influenced by knowledge from previous economics courses. The course in which we conducted our experiment was taught by an experienced instructor whose teaching style was supportive of international students. Specifically, partial lecture notes were provided online ahead of time which significantly reduced the note-taking burden for students, international and native alike. The instructor was aware of possible language gaps that many students might be experiencing and regularly provided definitions of words which might be unknown to international students.

During the term prior to the project start date, the English instructor attended the course to familiarize herself with course content, instructional activities, and key vocabulary. She used this knowledge and experience to develop pre- and post-reading and 
vocabulary assessments. An international economics graduate student was brought onto the project as a teaching assistant to provide content support to the English instructor and to act as a role model for the students.

We started off with a recruitment presentation in the economics class. Ten students volunteered to participate in our so-called 'EAL for Economics' tutorials of 1 1/2 hours of English instruction per week. This amount of time was selected as we felt that a longer session each week would discourage students from participating. We did not give additional homework or assessments for fear of overburdening the students. English tutorial materials were based on content from the economics classes. As there were few opportunities for discussion and writing in the larger economics classes, our EAL tutorials focused on the skills which were most relevant to our context and discipline, which were broadening and deepening vocabulary knowledge, reading strategies to enhance reading skills, note-taking, multiple choice exam strategies, and clarifying culturally bound references. In this way, our EAL tutorial materials were authentic in that they reinforced the skills required for success in the economics course.

The students demonstrated some interesting characteristics. While we recruited seven of the students, the remaining three came on their own by "word of mouth" from other sections. The group was evenly split between male and female students. In terms of academic background, they were generally strong students registered in demanding programs such as mathematics (6), computer science (2), or accounting and financial management (2). We feel that the heavy workloads of students prevented more of them from participating in the tutorials. To achieve a higher sample size, we would have needed institutional encouragement, perhaps in the form of mandatory participation.

In terms of language background, the students met the University's English language requirement for admission in varied ways. Three came from overseas and provided standardized English language test scores. Four had been in Canada less than three years, and met the requirement by submitting both standardized English test scores and secondary school
English grades. The remaining three had been in Canada more than three years and were not required to submit proof of English language proficiency beyond their secondary school English grades.

On close examination of these records, we found that their English language skills were not particularly strong. For those who submitted standardized English proficiency test scores, the average score was just below the University's minimum entrance requirement. Evidently, some were accepted with scores lower than the minimum requirement. For those who submitted secondary school English grades, the average score was 63\%. Overall, while their English backgrounds met University entrance requirements, they were not strong enough to ensure student confidence. The students were aware of their weaknesses in English, and they participated in our EAL tutorials because they aspired to the research objectives of enhancing both economics knowledge and English proficiency.

\section{Learning Outcomes}

The EAL tutorials provided a testing ground for combining economics and language instruction for international students. These were highly motivated students wishing to do well in their discipline and at the same time searching for ways to overcome their language barriers.

\section{English language assessments}

To determine the impact of the EAL tutorials on the students' language proficiency, we gave pre- and posttests on vocabulary and reading skills (available upon request from the corresponding author). Multiple choice vocabulary test items were based on lecture and textbook words that we anticipated students would not know. On the vocabulary assessments, we found that student performance improved between the two tests: the average score increased $13 \%$ from $55 \%$ to $68 \%$ while the minimum and maximum scores also moved up considerably (minimum from $28 \%$ to $44 \%$ and maximum from $76 \%$ to $88 \%$ ). The tutorials appeared to be an effective method to help international students develop their vocabulary skills. 
This result was reinforced by student comments during their exit interviews which provided qualitative insights into their perceptions of the effectiveness of the tutorials.

Pre- and post-test reading items were based on an economics text that provided introductory level economics content that students had not previously seen. The reading test results were less clear cut than the vocabulary test results: while the average score went down by $12 \%$ (69 to $57 \%$ ) and the minimum score fell $7 \%$ ( 47 to $40 \%$ ), the maximum score went up $6 \%$ (87 to $93 \%$ ). Thus, only the top performers did well. There are possible reasons for this outcome. For example, the falling average score may be due to what was perceived as the higher level of difficulty of the post-reading test compared to the prereading test. While measures were taken to ensure a consistent level of difficulty (texts matched in length and Flesch-Kincaid reading level), the students indicated in their exit interviews they felt the postreading test was more difficult. Another possible explanation lies with the lack of time for practicing time-consuming reading skills during the tutorials. While we recognize that longer EAL tutorials may have reduced the participation rate, more time practicing reading strategies may have yielded better post-test reading results.

\section{Economics content assessments}

The students' learning of economics content was measured by their final economics course grades. Their average was $85 \%$ which is well above the standard class average of $72 \%$ for most sections of introductory economics. The range of final grades was 74 to $91 \%$ with a standard deviation of $7 \%$. These grades suggest that the participants outperformed non-participating students although the fact that the participants volunteered for the project means that their success could be attributable to other factors such as motivation and hard work.

\section{Conclusions}

The following four lessons emerge from our experience of a pilot project to combine discipline- specific EAL instruction with the traditional method of course delivery in introductory economics: 1) discipline-specific EAL instruction, such as our 'EAL for Economics' tutorials, can help improve content and language learning; 2) vocabulary skills appear to be correlated to overall success in the economics test course; 3) reading skills may require more time to develop; and 4) our voluntary students valued the experience (as indicated in exit interviews.)

We recommend that work in disciplinespecific language instruction be continued to strengthen the literature on disciplinary versus generic approaches to language delivery in our teaching context. There certainly appears to be an opportunity to support the increasing numbers of international students in higher education.

It is worthwhile to note that success in interdisciplinary research is predicated upon a strong collaborative relationship between the researchers, which we feel we developed and enjoyed. We note that the students who volunteered in our project were highly motivated students looking for academic excellence, but non-participating students (who may have greater need for this support) may benefit even more than our voluntary group. We suggest that university level policy may be needed to encourage more student participation in future projects.

\section{References}

Baik, C. \& Greig, J. (2009). Improving the academic outcomes of undergraduate ESL students: the case for discipline-based academic skills program. Higher Education Research and Development, 28(4), 401-416.

Deen, J. \& Hacquebord, H. (2002). Contentbased language teaching. In M. Bax (Ed.), Reflections on language and language learning in honour of Arthur van Essen (pp. 221-236). Philadelphia: John Benjamins Publishing Company.

Grabe, W. \& Stoller, F. L. (1997). Content-based instruction: Research foundations. In M.A. 
Snow \& D.M. Brinton (Eds.), The contentbased classroom: perspectives on integrating language and content (pp. 5-21). New York: Longman.

Hyland, K. (2002). Specificity revisited: How far should we go now? English for Specific Purposes, 21, 385-395.

Kasper, L.F. (1997). The impact of content-based instructional programs on the academic progress of ESL students. English for Specific Purposes, 16 (4), 309-320.

North, S. (2005). Different values, different skills? A comparison of essay writing by students from arts and science backgrounds. Studies in Higher Education, 30 (5), 517-533.

Ready, D. \& Wesche, M. (1992). An evaluation of the University of Ottawa's sheltered program: Language teaching strategies that work. In R.J. Courchêne, J. Gliden, J. St-John, \& C. Thérien (Eds.), Comprehension-based second language teaching (pp. 389-405). Second Language Institute, University of Ottawa.

Rodgers, D.M. (2006). Developing content and form: Encouraging evidence from Italian content-based instruction. The Modern Language Journal, 90(3), 373-386.

Song, B. (2006). Content-based ESL instruction: long-term effects and outcomes. English for Specific Purposes, 25, 420-437.

\section{Biographies}

Trien Nguyen is a Professor of Economics at the University of Waterloo, with research interests in economics, technology, and the scholarship of teaching and learning.

Angela Trimarchi is Lecturer of Economics at the University of Waterloo and Wilfrid Laurier University, with several years of experience in teaching economics to international students.

Julia Williams is the Assistant Director (Credit programs) of the English Language Institute at Renison University College, the University of Waterloo. Her research interests include Content and Language Integrated Learning. 